\title{
A New Genus of the Actinomycetales: Microtetraspora gen.nov.
}

\author{
By J. E. THIEMANN, H. PAGANI AND GRAZIA BERETTA \\ Research Laboratories, Lepetit S.p.A., Milan, Italy
}

(Accepted for publication 4 August 1967)

\begin{abstract}
SUMMARY
Two aerobic mesophilic microbial species of a new genus belonging to the family Streptomycetaceae of the order Actinomycetales are described under the name Microtetraspora (Microtetraspora glauca, type species). The microorganisms produced a filamentous growth which is differentiated into a vegetative and an aerial mycelium.

The new genus is characterized by the formation of a short and sparsely branched aerial mycelium bearing at the end of short sporophores chains of four spores. Sporulation is not observed to take place on the vegetative mycelium. The genus Microtetraspora is widely distributed in the soil and has been isolated from many samples.
\end{abstract}

\section{INTRODUCTION}

The number of genera of the actinomycetes, or ray fungi, has increased considerably in the last few years reflecting a continued interest in these micro-organisms. Thus, while at the time of the latest edition of Bergey's Manual (1957) only three genera had been recognized in the Streptomycetaceae, by 196I Waksman listed the following six genera: Streptomyces, Thermoactinomyces, Microbispora (Waksmania), Thermopolyspora, Micromonospora and Thermomonospora.

The present paper reports the isolation and description of two strains of actinomycetes which were easily distinguished from the known genera of the Streptomycetaceae by their unusual mode of sporulation: a chain of four spores was formed on short sporophores developing on monopodially branched short strands of aerial mycelium. The strains differed significantly from the previously described genera in the family Streptomycetaceae and it is therefore proposed to include them in a new genus to which the name Microtetraspora gen.nov. is given. The type species of the genus is Microtetraspora glauca (ATCC 23057) a subculture of which has been deposited with the American Type Culture Collection, together with Microtetraspora fusca (ATCC 23058) the second species isolated.

\section{METHODS}

A recently developed novel method for the mass isolation of little-known soil micro-organisms belonging to the Actinomycetales was used (Thiemann, in preparation). With this method the large-scale isolation of Microbispora, Streptosporangium, Actinoplanes, Microtetraspora, and species of other not yet described new genera has been made possible. A detailed description of this method will be published separately elsewhere.

Stains. The staining procedures recommended by the Society of American Bacteriologists (1957) were used. 
Photographs. Microphotographs were taken with a Zeiss binocular microscope, model Standard WL, with Optovar and $35 \mathrm{~mm}$. photomicrography attachment. Kodak Plus X Pan film was used. Electron photomicrographs of sporulated mycelium were taken with a Hitachi model HU-II electron microscope by touching collodion films mounted on grids onto cultures growing on soil agar incubated at $30^{\circ}$. Sporulation was studied also by growing the cultures directly on collodion membranes according to the technique described by Grein (1955).

Culture media. Unless otherwise stated the media used were prepared according to Waksman (196I).

Soil agar. Air-dried garden soil passed through a Io-mesh sieve, $30 \mathrm{~g}$., agar $20 \mathrm{~g}$., tap water to $1000 \mathrm{ml}$., $\mathrm{pH} 6.0$. Sterilized for $20 \mathrm{~min}$. at $\mathrm{I} 20^{\circ}$.

Examination of spore germination. The spores from a fully sporulated agar slant culture were carefully scraped off with a sterile loop and streaked on to the surface of soil extract agar plates and soil agar plates. The plates were incubated at $28^{\circ}$ and examined directly under the microscope for the appearance of germ tubes.

Preparation and analysis of cell walls. The organisms were grown in the seed medium of Margalith \& Pagani (196I) and incubated at $28^{\circ}$ on a rotary shaker (250 rev./min.). After $48 \mathrm{hr}$ of growth the cells were collected by centrifugation and thoroughly washed with distilled water. After treatment with ethanolic $\mathrm{KOH}(0.5 \%)$ at $37^{\circ}$ for $24 \mathrm{hr}$ the cells were washed with ethyl alcohol until the $\mathrm{pH}$ value was neutral. Suspensions of cells were disrupted by agitating them for $48-72 \mathrm{hr}$ on a rotary shaker ( $250 \mathrm{rev} . / \mathrm{min}$.) with an equal volume of glass beads $(\mathrm{I} \cdot \mathrm{O}-\mathrm{I} \cdot 5 \mathrm{~mm}$. diam.). A few $\mathrm{ml}$. chloroform were added to avoid bacterial contamination. The degree of breakage was checked by phase microscopy. For all the other steps the methods described by Becker, Lechevalier \& Lechevalier (1965) were followed.

\section{RESULTS}

Description of Microtetraspora Thiemann, Pagani and Beretta gen.nov.

Morphology. The fine mycelium (about I $\mu$ diam.) differentiated into: (I) vegetative (primary) mycelium which was profusely branched, grew into the agar medium and formed a compact layer on top of it; (2) aerial (secondary) mycelium arising from the vegetative mycelium which grew into the air away from the agar surface. Spores were formed only on the aerial hyphae and never on the vegetative mycelium. The spores were formed in chains of four on short sporophores, which branched characteristically from the aerial hyphae at an angle of $45^{\circ}$, giving to the sporophores, when examined en masse, an appearance reminiscent of an ear of wheat (Pl. I, fig. I).

Description of Microtetraspora glauca ATCC 23057 and Microtetraspora fusca ATCC 23058 Thiemann, Pagani and Beretta, sp.nov.

Of the various cultures of Microtetraspora isolated, strain T I58 and strain T 457 were selected as the type strain of the species $M$. glauca and $M$. fusca respectively. No qualitative differences were found in the microscopic properties of $M$. glauca and $M$. fusca; the two isolates are, however, easily distinguished by their cultural and biochemical characteristics which are shown in Table I and Table 2 respectively. The following general morphological description applies equally to both cultures.

Vegetative mycelium. About $0 \cdot 7-1 \cdot 0 \mu$ diam. Filaments long, wavy, branching, penetrating the agar and forming on its surface, compact, raised and tough colonies 
like those of typical Streptomyces spp. The main (older) mycelium strands are larger $(\mathrm{I} \cdot \mathrm{O} \mu)$ and have a granulated appearance. The mycelium does not fragment even in old cultures.

Aerial mycelium. Approximately $\mathrm{I} \cdot 0 \mu$ in diam. The hyphae emerging from the vegetative mycelium are erect, sparsely branched and rather short, usually not exceed-

\section{Table I. Cultural characteristics of Microtetraspora glauca strain T158 and $M$. fusca strain T457}

G. growth; V.m. vegetative mycelium; A.m. aerial mycelium; Sp. sporulation. Soluble pigments were not formed on any of the media examined. Colours were determined according to Maerz \& Rea Paul (I950).

Culture media

Glucose asparagine agar

Glycerol asparagine agar

Calcium malate agar

Soil agar

Bennett agar

Oatmeal agar

Nutrient agar

Carrot plug

Potato plug

Czapek agar
M. glauca strain T 158 (ATCC 23057)

G. moderate, flat

V.m. ash grey (pl. 27, A-2)

A.m. sparse to absent

Sp. absent

G. poor, flat

V.m. hyaline

A.m. absent

Sp. absent

G. very poor, flat

V.m. hyaline

A.m. sparse

Sp. poor

G. very good, elevated

V.m. blue green (pl. 25, J-6) to yellowish green (pl. 2I, J-I)

A.m. abundant, pearl grey

(pl. 44, A-I)

Sp. good

G. moderate, flat

V.m. hyaline to ash grey (pl. 27, A-2)

A.m. white grey (pl. I I, A-I)

Sp. very good

G. very good

V.m. blue green (pl. 26, K-5)

to yellowish green (pl. 20, K-I)

A.m. grey (pl. 28, C-I)

Sp. moderate

G. good, flat

V.m. blue green (pl. 30, G-I)

A.m. blue grey (pl. 28, L-I)

Sp. good

G. moderate

V.m. cream (pl. 9, D-2)

A.m. absent

Sp. absent

G. no growth

G. no growth

G. no growth
M. fusca strain T457

(ATCC 23058)

G. good, smooth

V.m. hyaline

A.m. white grey (pl. I I, A-I)

Sp. good

G. good, smooth

V.m. hyaline

A.m. white grey (pl. II, A-I)

Sp. good

G. poor, flat

V.m. hyaline

A.m. white grey (pl. II, A-I)

Sp. good

G. very good, wrinkled

V.m. brown violet (pl. 8, L-8)

A.m. good, white grey (pl. I I, A-r)

Sp. good

G. moderate, flat

A.m. white grey (pl. I I, A-I)

Sp. very good

G. very good, wrinkled

V.m. amber with reddish tinge

(pl. 12, B-9)

A.m. white grey (pl. I I, A-I)

Sp. very good

G. very poor, flat

V.m. hyaline

A.m. scarce to absent

Sp. absent

G. very good, elevated

V.m. amber (pl. 12, F-7)

A.m. absent

Sp. absent

G. very poor; wrinkled

V.m. cream (pl. 9, D-2)

A.m. absent

G. very poor; wrinkled

V.m. cream (pl. 9, D-2)

A.m. absent

G. no growth 
ing $50 \mu$. On rich media, such as Hickey and Tresner agar or even oatmeal agar, coremium-like formations of the aerial mycelium can be seen.

Sporophores. The sporophores are formed as thin $(0.5 \mu)$ monopodial branches of the aerial hyphae. The sporophores can be relatively long $(5.5 \mu)$ but normally are only I $\cdot 0-2 \cdot 0 \mu$ in length (Pl. I, fig. 2). Occasionally the sporophores are extremely short, giving the impression that the spores are attached directly to the hypha. The sporophores of $M$. fusca tend to fuse into more or less globular masses of spores as the culture ages (Pl. I, fig. 3).

Table 2. Biochemical characteristics of Microtetraspora glauca strain $T 158$ and $M$. fusca strain T457

\begin{tabular}{|c|c|c|}
\hline & $\begin{array}{l}\text { M. glauca strain T I } 58 \\
\text { (ATCC 23057) }\end{array}$ & $\begin{array}{l}\text { M. fusca strain T } 457 \\
\text { (AT CC23058) }\end{array}$ \\
\hline Nitrate reduction & Reduced & Not reduced \\
\hline Tyrosine agar & Not hydrolysed; no melanoid pigment & $\begin{array}{l}\text { Not hydrolysed; no melanoid } \\
\text { pigment }\end{array}$ \\
\hline Skim milk agar & Casein slowly digested & Casein slowly digested \\
\hline $\mathrm{H}_{2} \mathrm{~S}^{*}$ & Positive & Positive \\
\hline Gelatin & Completely hydrolysed & Not hydrolysed \\
\hline Starch & Slight hydrolysis & Not hydrolysed \\
\hline Litmus milk & No coagulation, no peptonization & No coagulation, no peptonization \\
\hline Peptone iron agar & No melanoid pigment & No melanoid pigment \\
\hline
\end{tabular}

Spores. Spores are formed in chains of four. Mature spores are spherical $(\mathrm{I} \cdot 5 \mu)$ to slightly oval $(\mathrm{I} \cdot 4 \times \mathrm{I} \cdot 7 \mu)$. No spines or hairs are present on the spore surface (Pl. I, fig. 4). Immature spores are rather variable, being somewhat cuboid $(0.8 \times 0.8 \mu)$ or even triangular, as a result of their mode of formation; the central ones tending to be compressed and cuboid and the ones at the extremities of the spore chain are sometimes triangular (Pl. I, fig. 5). The immature spores when examined under the oilimmersion lens give the impression of being 'empty' and present a central highly refractile spot; fully developed and mature spores are uniformly dark, opaque, spherical to oval and usually without refractile spots (Pl. I. fig. 6). Spores are formed only on the aerial hyphae and never on the vegetative mycelium. Occasionally in old cultures on soil agar plates, spores come in contact with the agar surface and germinate giving the impression that they are formed on the vegetative mycelium.

Spore formation. Spore formation begins by a terminal enlargement of the aerial hyphae, the cytoplasm of which condenses giving a bead-like appearance. In some preparations, transverse septa separating the spores can be seen (Pl. 2, fig. 7), in others the early separation of the spores is indicated only by an area of higher refringence. Four spores are usually formed in each chain but in some instances chains with only two or three spores are formed and very rarely chains of five spores. The four spores of a sporophore do not always grow uniformly and attain the same size; sometimes mature spores of variable size and immature ones occur in the same chain. Usually the four spores of the sporophore are formed in a single plane; however, occasionally the two spores at the top of the sporophore are placed eccentrically in relation to the other two. Sporulation in the genus Microtetraspora appears to proceed from the base of a fertile branch towards its tip, since transverse septa, when observed, were always seen to be formed first at the base of the fertile branch (Pl. 2, fig. 8). The spores when 
transferred to fresh medium germinate and produce one to four rather large germ tubes. The germinated spores are clearly visible in the matted mycelium even $72 \mathrm{hr}$ after germination (Pl. 2, fig. 9).

Staining. Young mycelium grown under submerged conditions was used for the staining reactions. The mycelium of Microtetraspora glauca and $M$. fusca was Grampositive and was not acid-fast.

Effect of temperature and $\mathrm{pH}$ on growth. The effect of temperature on growth was investigated by incubating inoculated Petri dishes (Bennett agar, oatmeal agar and Hickey \& Tresner agar) at $22^{\circ}, 28^{\circ}, 37^{\circ}, 45^{\circ}$, and $50^{\circ}$. Microtetraspora glauca grew equally well on all three media at $22^{\circ}$ and $37^{\circ}$, but was optimal at $28^{\circ}$, whereas $M$. fusca grew better at $28^{\circ}$ and $37^{\circ}$ than at $22^{\circ}$. Neither $M$. glauca nor $M$. fusca developed at $45^{\circ}$ or $50^{\circ}$. To test for the effect of $\mathrm{pH}$ on growth, the above media were corrected to $\mathrm{pH} 4,5,6,7$ and 8 , inoculated and incubated at $28^{\circ}$. Under these conditions $M$. glauca did not grow at $\mathrm{pH}_{4}$; at $\mathrm{pH}_{5}$ it was sparsely developed, whereas at $\mathrm{pH} 6,7$ and 8 good development was observed on all three media. Microtetraspora fusca on the other hand, grew equally well at $\mathrm{pH} 6$ and 7 , and only sparsely at $\mathrm{pH} 5$ and 8 . No growth took place at $\mathrm{pH} 4$.

Utilization of carbon sources. Microtetraspora glauca and $M$. fusca did not develop on the standard minimal media employed in the carbon utilization tests. Positive results were obtained using the synthetic medium of Magni \& von Borstel (I962) to which a vitamin B mixture $(0.2 \gamma / \mathrm{ml})$ was added. Since on this medium the control plates (no carbon source) showed a moderate amount of growth as well, carbon utilization was considered negative when the growth was similar to or less than the growth on medium without a carbon source. Under these conditions, arabinose, xylose, glucose, galactose, fructose, mannose and ribose supported good growth of $M$. glauca, whereas rhamnose, maltose, saccharose, mannitol, inositol and starch supported only moderate to sparse growth. No growth was supported by lactose, raffinose, glycerol, sorbitol, dulcitol, inulin and sorbose. On the other hand $M$. fusca grew only in presence of arabinose, xylose, glucose, ribose, inulin and maltose. With all the other carbon sources, no visual difference between the control plates was observed.

Table 3. Major components of cell-wall preparations of various form genera of Actinomycetales showing some morphological similarity with Microtetraspora

\begin{tabular}{|c|c|c|c|c|c|c|c|}
\hline \multirow[b]{2}{*}{ Genera } & \multicolumn{2}{|c|}{ DAP acid } & \multicolumn{3}{|c|}{ Sugars and amino-sugars } & \multicolumn{2}{|c|}{ Amino acids } \\
\hline & LL & Meso & Galactose & Galactosamine & Arabinose & Glycine & Lysine \\
\hline Streptomyces* & + & - & - & - & - & + & - \\
\hline Microellobosporia* & + & - & - & - & - & + & - \\
\hline Microbispora* & - & + & - & - & - & $(+) \dagger$ & - \\
\hline Micropolyspora* & - & + & + & - & + & - & - \\
\hline Microtetraspora & \pm & + & - & + & - & + & + \\
\hline
\end{tabular}

All genera had in common: muramic acid, glucosamine, glutamic acid and alanine.

* Data from Becker, Lechevalier \& Lechevalier (I965).

$\dagger$ Only some strains do contain glycine.

Cell-wall composition. Chemical analysis of cell-wall preparations of Microtetraspora showed them to contain, as major components, meso-diaminopimelic acid, glucosamine, galactosamine, muramic acid, glycine, glutamic acid, alanine and lysine. 
LL-diaminopimelic acid was always present, however, in small amounts. In Table 3 the cell-wall components of the various form-genera of the Actinomycetales showing some morphological similarity with Microtetraspora are given. As can be seen from this table, the cell walls of Microtetraspora differ considerably in their composition from the cell walls of the other genera described in the literature and with which Microtetraspora has some morphological affinity.

Source. Microtetraspora glauca was first isolated from a soil sample collected from the vicinity of carrot roots at Appiano Gentile, Como, Italy, and $M$. fusca from a sample received from Thailand and collected on a rubber plantation in the Province of Amphur Sadao, Songkhla. Species of Microtetraspora are, however, widespread in nature and have been isolated from many of the soil samples so far examined, received from various parts of Italy, Thailand and Brazil.

\section{DISCUSSION}

The growth characteristics on different nutrient media and the mode of spore formation indicate that the new genus Microtetraspora should be included in the family Streptomycetaceae. The characteristic production of a linear chain of four spores on the aerial mycelium differentiated these cultures from the previously described species that we have found in the literature and from those that we have isolated and studied up till now.

The genus Micropolyspora described by Lechevalier, Solotorovsky \& McDurmont (196I) and characterized by the formation of chains of spores both on the aerial and on the vegetative mycelium differs from Microtetraspora not only in the formation of spores on the vegative mycelium but also in the overall morphology of the sporophores and aerial mycelium. Whereas in Microtetraspora as a rule, chains of 4 spores are formed, attached to the hypha by short sporophores, in Micropolyspora spore chains of up to Io spores are not uncommon. Stolon-like structures formed by the long and branching hyphae of the aerial mycelium have also been described for Micropolyspora as well as for the genus Microbispora. Two new genera recently described having a short row of spores are Microellobosporia (Cross, Lechevalier \& Lechevalier, 1963) and Microechinospora (Koniev, Tsyganov, Minbayev \& Morozov, 1965). Microellobosporia which belong to the Actinoplanaceae is characterized by the production of large $(\mathrm{I} \cdot 5-3.5 \mu)$ and non-motile sporangiospores arranged in a single straight row inside a sporangium formed both on the aerial and on the vegetative mycelium. The same genus was described simultaneously by Russian workers under the name Macrospora (Tsyganov, Zhukova \& Timofeeva, I963). The genus Microechinospora characterized by the formation on the aerial as well as on the vegetative mycelium of a straight row of large spherical spores $(2 \cdot 5-3.5 \mu)$ enclosed in a clubshaped sporangium having a characteristically spiny surface is also included in the Actinoplanaceae. The genus Microechinospora closely resembles the genus Microellobosporia from which it is differentiated mainly by the spiny surface of the sporangia. The mode of sporulation, size of the spores, and sporangia formation clearly distinguish these genera from Microtetraspora. Thorough examination of stained and unstained preparations of Microtetraspora with the optical as well as electron microscope (Pl. I, fig. 4; Pl. 2, fig. I0) failed to reveal any indication of sporangia formation.

Recently, Lechevalier \& Lechevalier (1965) proposed a classification of the aerobic 
actinomycetes based on their morphology as well as on the chemical composition of their cell walls. On the basis of their data these authors grouped the euactinomycetes as follows. Family Dermatophilaceae, one genus, Dermatophilus; Family Actinoplanaceae, 6 genera, Actinoplanes, Ampullariella, Spirillospora, Streptosporangium, Amorphosporangium and Microellobosporia; Family Streptomycetaceae, one genus, Streptomyces; Family Micromonosporaceae one genus, Micromonospora; Family Nocardiaceae Fam.nov., 6 genera, Thermoactinomyces, Thermomonospora, Microbispora, Micropolyspora, Pseudonocardia and Nocardia. In the genus Streptomyces sensu lato of Lechevalier \& Lechevalier (1965) were included the various forms desscribed as Streptoverticillium, Chainia and Actinopycnidium. The cell-wall preparations from the organisms belonging to this genus contained only glucosamine, muramic acid, alanine, glutamic acid, glycine and LL-diaminopimelic acid. In recent years the cellwall composition of the actinomycetes has been frequently used as an aid in their classification. Whether the classical taxonomic approach of Waksman (I96I) to the classification of the actinomycetes is to be preferred to the new and undoubtedly also more objective approach of Lechevalier \& Lechevalier (I965) is beyond our scope. It suffices to mention, however, that when atypical Streptomyces and Nocardia are examined only for their morphological and cultural characters it is often entirely a matter of personal preference whether an isolate is placed in one genus or the other (Waksman, 196I). In these dubious cases, the chemical approach to the classification has already proved to be of great value (Becker, Lechevalier, Gordon, \& Lechevalier 1964; Becker et al. 1965).

Analysis performed on cell-wall preparations of Microtetraspora brought to light some interesting data. The presence of small but reproducible amounts of LL-diaminopimelic acid, the presence of glycine, and the absence of characteristic sugars in the cell-wall hydrolysates of Microtetraspora is an interesting feature shared also by the cell walls of Streptomyces spp.

On the other hand, the composition of the cell walls of Microtetraspora shows also some similarities with the one of Microbispora; the presence of galactosamine and lysine, apart from the small amount of LL-diaminopimelic acid, distinguishes nevertheless the cell walls of these two genera. On the basis of these overall similarities it is possible to think of Microtetraspora as forming a link between the Streptomyces and Microtetraspora. Apart of this hypothetical phylogenetic relationship between Microtetraspora and some of the other genera of the Actinomycetales, it is important to bear in mind that in addition to the morphological features which distinguish Microtetraspora from the genera already described, it differs from them also in the cellwall composition.

The following revision of the existing key to the family Streptomycetaceae sensu Waksman (I96I) is proposed to accommodate Microtetraspora:

I. Aerial (secondary) mycelium formed

a. Spores formed in chains mainly on the aerial mycelium, rarely also on the substrate mycelium (Becker, Lechevalier \& Lechevalier, 1965).

Streptomyces Waksman \& Henrici

b. Spores formed in chains, both on the aerial and substrate mycelium.

Micropolyspora Lechevalier, Solotorovsky \& McDurmont

c. Spores formed in chains of four on short sporophores on the aerial mycelium only.

Microtetraspora gen.nov. Thiemann, Pagani \& Beretta 
d. Spores occurring singly, in pairs or in chains

a I. Mesophilic forms, spores in pairs on sporophores on the aerial mycelium and with rare exception also on the substrate mycelium (Becker, Lechevalier \& Lechevalier, 1965).

Microbispora Nonomura \& Ohara

b I. Thermophilic forms:

I. Spores single on sporophores both on the aerial and substrate mycelium.

2. Spores single on aerial mycelium only.

Thermoactinomyces Tsiklinsky

rial (secondary) mycelium not produced.

a. Spores occurring singly on short sporophores.

Thermomonospora Henssen

The genus Thermopolyspora (Henssen, 1957), of questionable validity (Krasilnikov, 1964; Becker et al. 1965; Lechevalier, 1965), has been omitted since its characterization was based on cultures contaminated with bacteria of unknown nature and her original cultures of Thermopolyspora polyspora are now dead, and according to Rule $24 \mathrm{~g}$ of the International Code of Nomenclature of Bacteria and Viruses (I958): 'A name of a taxon is illegitimate... if the characterization of the group was based upon an impure or mixed culture.' The new thermophilic genus Actinobifida, isolated by Krasilnikov \& Agre (1964), has also been omitted. This genus is characterized by the formation of single spores borne on the tip of dichotomously branching sporophores arising from the hyphae of the aerial mycelium or from the surface of the colony. This genus was included by Krasilnikov \& Agre (1964) in the family Micromonosporaceae, it is felt, however, that it would be more properly included among the thermophilic forms (Thermoactinomyces, Thermomonospora). Where Actinobifida will finally be placed has to await the results of more detailed comparative studies between Actinobifida and the other actinomycetes which form single isolated spores on the aerial mycelium.

Twelve soil samples out of a total of 53 different ones so far examined and received from various parts of the world yielded strains of Microtetraspora. A total of I 34 strains were isolated. This relatively large number of strains isolated can be taken as an indication of the cosmopolitan distribution of this genus. At present no indications of the possible role these micro-organisms might play in the soil are at hand.

The authors are grateful to Prof. E. Baldacci, Director of the Istituto di Patologia Vegetale, Università degli Studi of Milan, for making the electron microscope available to them. The valuable collaboration of Dr G. Farina of the same Institute, in carrying out the electron micrographs is gratefully acknowledged. Thanks are also due to Dr G. Pelizza and Dr G. Zucco of these Laboratories for their assistance in performing the cell-wall analysis.

\section{REFERENCES}

Becker, B., Lechevalier, M. P. \& Lechevalier, H. A. (1965). Chemical composition of cell-wall Appl. Microbiol. 12, $42 \mathrm{I}$.

Becker, B., Lechevalier, M. P., Gordon, R. E. \& Lechevalier, H. A. (I964). Rapid differentiation between Nocardia and Streptomyces by paper chromatography of whole-cell hydrolysates. preparations from strains of various form-genera of aerobic actinomycetes. J. Bact. 13, 236.

Bergey's Manual of Determinative Bacteriology (1957). 7 th ed. Ed. by R. S. Breed, E. G. D. Murray and N. R. Smith. Baltimore: The Williams and Wilkins Co.

Cross, T., Lechevalier, M. P. \& Lechevalier, H. A. (1963). A new genus of the Actinomycetales: Microellobosporia gen.nov. J. gen. Microbiol. 3I, $42 \mathrm{I}$.

GreIN, A. (1955). Una tecnica per l'osservazione di attinomiceti al microscopio elettronico Lab. Scient. 3, 88 . 
Journal of General Microbiology, Vol. 50, No. 2

Plate I
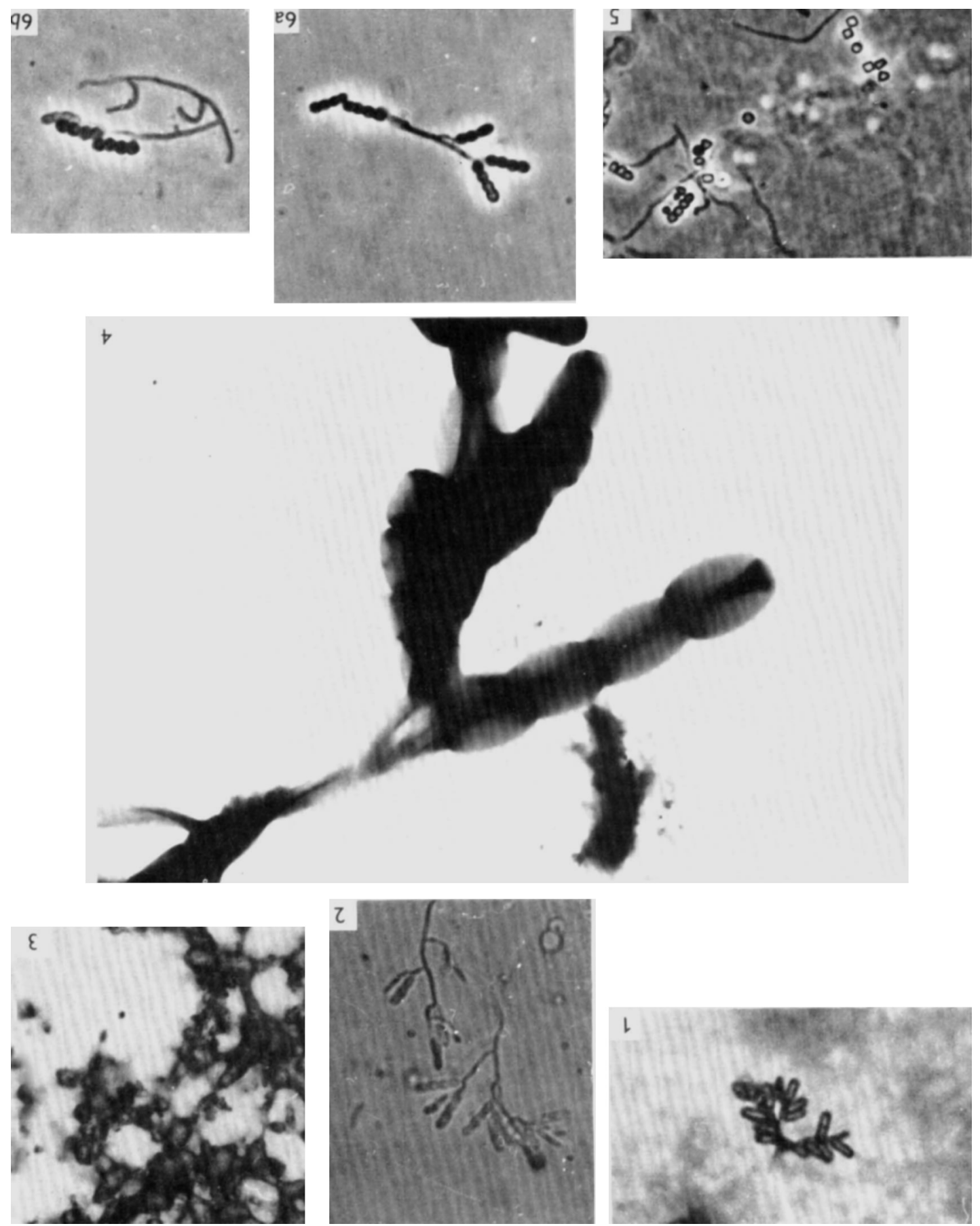

J. E. THIEMANN, H. PAGANI AND G. BERETTA

(Facing p. 302) 

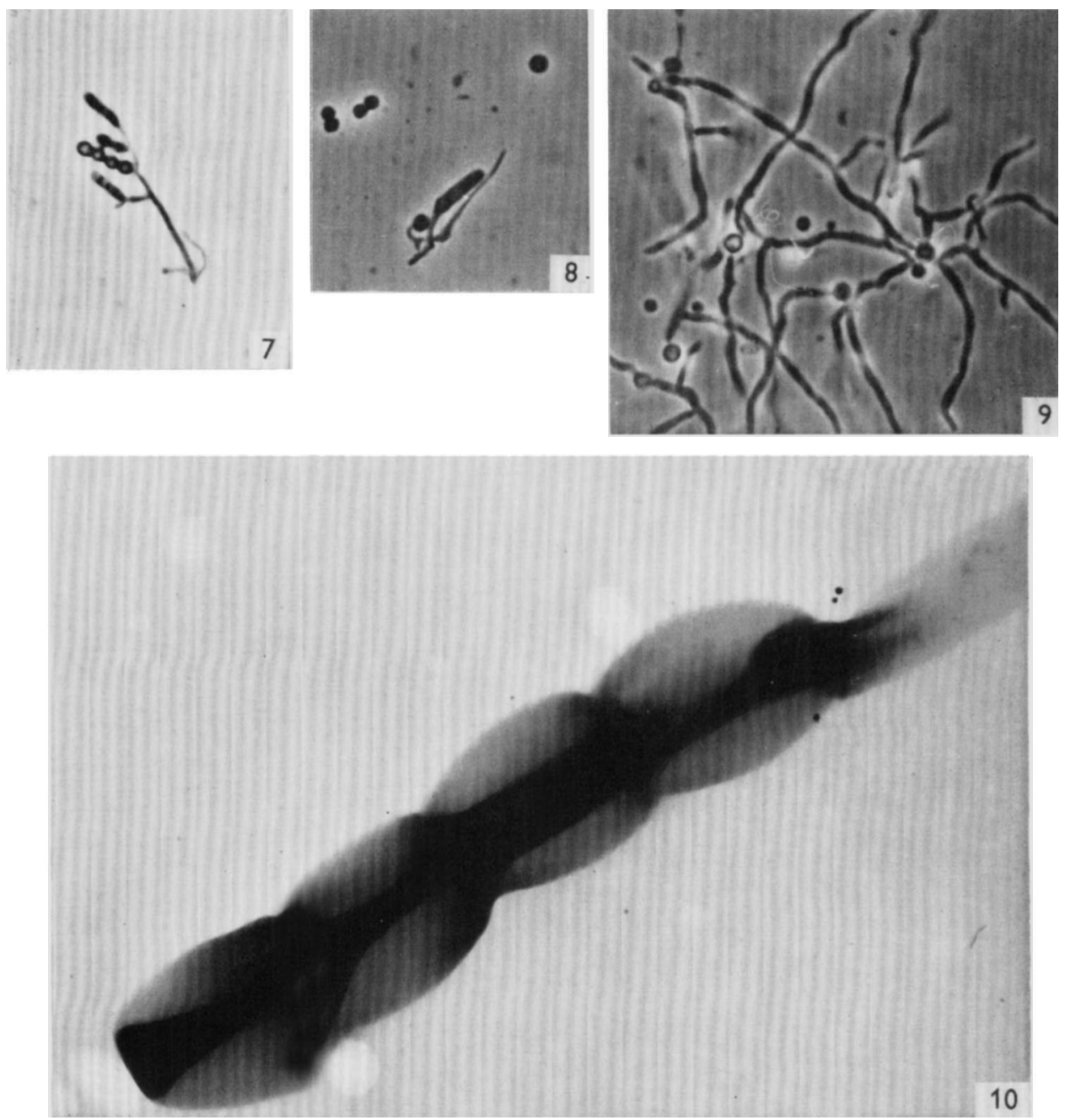

J. E. THIEMANN, H. PAGANI AND G. BERETTA 
Henssen, A. (1957). Beiträge zur Morphologie und Systematik der thermophilen Actinomyceten. Arch. Mikrobiol. 26, 373.

Koniev, Yu. E., Tsyganov, V. A., Minabayev, P. \& Morozov, V. M. (1965). Isolation of a new genus of the Actinomycetes, Microechinospora gen.nov. 4th Scientific Conference of the Leningrad Institute of Antibiotics, p. 8o. (In Russian.)

Krasilnikov, N. A. (1964). Systematic position of ray fungi among the lower organisms. Hindustan Antibiot. Bull. 7, I.

Krasilnikov, N. A. \& Agre, N. S. (1964). A new genus of Actinomycetes-Actinobifida n.gen. The yellow group-Actinobifida dichotomica n.sp. Mikrobiologiya 33, 935.

Küster, E. \& Williams, S. T. (1964). Production of hydrogen sulfide by Streptomycetes and methods for its detection. J. appl. Microbiol. 12, 46.

LeChevalier, H. A. (I965). Priority of the generic name Microbispora over Waksmania and Thermopolyspora. Int. Bull. bact. Nomen, Taxon. $15,139$.

Lechevalier, H. A. \& Lechevalier, M. P. (1965). Classification des actinomycètes aërobies basée sur leur morphologie et leur composition chimique. Annls Inst. Pasteur, Paris, 108, 662.

Lechevalier, H. A., Solotorovsky, M. \& MCDurmont, C. (1961). A new genus of the Actinomycetales: Micropolyspora gen.nov. J. gen. Microbiol. 26, I I.

Maerz, A. \& Rea Paul, M. (1950). A Dictionary of Colour. New York: McGraw-Hill Inc.

MAGNi, G. E. \& voN Borstel, R. C. (1962). Different rates of spontaneous mutation during mitosis and meiosis in yeast. Genetics 47,1097 .

Margalith, P.\& Pagani, H. (1961). XIII. Fermentation and production of rifomycin complex. Appl. Microbiol. 9, 320.

Society of American Bacteriologists (1957). Manual of Microbiological Methods. New York: McGrawHill, Inc.

Tsyganov, V. A., Zhukova. R. A. \& Timofeeva, K. A. (I963). A new genus of actinomycetes Macrospora, gen. nov. 3rd Scientific Conference of the Leningrad Institute of Antibiotics, Leningrad. (In Russian.)

Waksman, S. A. (1961). The Actinomycetes, vol. 2. The William and Wilkins Co.

\section{EXPLANATION OF PLATES}

Plate I

Fig. I. Microtetraspora glauca on soil agar plates. Low-power magnification ( $\times$ I I 20$)$ of the aerial mycelium and spore bearing hyphae.

Fig. 2. M. glauca; aerial mycelium showing mature spores as well as spore chains in different stages of development (soil plate-direct microscopical examination, $\times 3500$ ).

Fig. 3. M. fusca; spore-fusion into globular masses; Ca malate agar.

Fig. 4. M. glauca; electron micrograph of aerial mycelium with sporophores (soil plate, $\times$ 10370).

Fig. 5. M. fucsa; disrupted chains of spores showing the variable morphology of the still immature spores $(\times 3500$.

Fig. 6. M. glauca; aerial mycelium with fully developed spores (soil plates, $\times 3500$ ).

\section{Plate 2}

Fig. 7. Microtetraspora glauca; different stages of spore formation. Transverse septa are clearly seen (soil plates, $\times 3500$ ).

Fig. 8. M. glauca; formation of transverse septa at the base of the sporophore giving rise to spore formation $(\times 3500)$.

Fig. 9. M. glauca; spore germination on soil extract agar after $38 \mathrm{hr}$ at $28^{\circ}(\times 3500)$.

Fig. Io. M. glauca; electron micrograph of isolated spore chain (soil plate, $\times 22,100$ ). 
